Int. J. Electrochem. Sci., 16 (2021) Article ID: 210228

International Journal of

ELECTROCHEMICAL

SCIENCE

$\underline{\text { www.electrochemsci.org }}$

\title{
Investigation of 5-aminosalicylic acid (Mesalazine Drug) as a Corrosion Inhibitor for Carbon Steel in Sulfuric Acid Solution
}

\author{
Hossein Movahedinia, Mehdi Shahidi-Zandi ${ }^{*}$,Maryam Kazemipour \\ Department of Chemistry, Kerman Branch, Islamic Azad University, Kerman, Iran \\ "E-mail: meshahidizandi@gmail.com
}

doi: $10.20964 / 2021.02 .29$

Received: 2 September 2020 / Accepted: 31 October 2020 / Published: 31 December 2020

\begin{abstract}
The techniques of polarization, electrochemical impedance spectroscopy (EIS) and Fourier transform infrared (FTIR) spectroscopy were employed for investigating the behavior of mesalazine drug (5aminosalicylic acid) on the corrosion protection of carbon steel in $0.5 \mathrm{M} \mathrm{H}_{2} \mathrm{SO}_{4}$ solution. The corrosion protection was increased with increasing mesalazine concentration in both acid solutions. As evidenced by polarization data, mesalazine behaves as a mixed-type inhibitor and retards both anodic and cathodic processes. The inhibition efficiency of the drug decreased as the temperature increased up to $55^{\circ} \mathrm{C}$. The activation energies for the corrosion of carbon steel in the sulfuric acid solution were increased in the presence of the drug. The thermodynamic parameters for the corrosion process of carbon steel in sulfuric acid medium were calculated from the effect of temperature on the corrosion process. The adsorption of mesalazine on carbon steel in acid solution obeyed the Langmuir adsorption isotherm. The results extracted from the polarization data were in agreement with those obtained from EIS data. FTIR spectroscopy revealed the possible active center sites of mesazaline molecule during adsorption on the steel surface.
\end{abstract}

Keywords: Mesalazine drug; Potentiodynamic polarization; Electrochemical impedance spectroscopy; Green inhibitor.

\section{$\underline{\text { FULL TEXT }}$}

(C) 2021 The Authors. Published by ESG (www.electrochemsci.org). This article is an open access article distributed under the terms and conditions of the Creative Commons Attribution license (http://creativecommons.org/licenses/by/4.0/). 